\title{
Die filosofie van Immanuel Kant en Protestants-teologiese denkstrukture
}

\author{
P S Dreyer \\ Emeritus Professor, Universiteit van Pretoria
}

\begin{abstract}
The philosophy of Immanuel Kant and Protestant theological structures
\end{abstract}

Kant's critical epistemology destroyed the idea of scientific metaphysics (valid up to Wolff) as the foundation of theology. Kant, however, reconstructed his own metaphysics on the basis of practical reason. In this scheme metaphysics and ethics are interwoven and culminate in a religion exclusively based on and conditioned by pure reason, usually known as Kant's moral theology or rational religion. The purpose of this paper is, firstly, to give a very short exposition of the basic concepts of Kant's moral theology, and secondly, to show its decisive influence on post Kantian protestant view of religion.

Dat die laaste en diepste werklikheid vir die menslike rede bereikbaar en deurdringbaar is, was vir die belangrikste Griekse wysgere vanselfsprekend. Die kenbaarheid van God, of die hoogste allesomvattende Idee, die Idee van skoonheid, waarheid en goedheid, word nooit deur Plato betwyfel nie, en Aristoteles beskryf met ewe groot sekerheid die plek en funksie van die Onbeweegde Beweër.

Ondanks die teenstand van teoloë soos Tertullianus het Justinus die Martelaar reeds begin om Christelike geloofsoortuigings en Griekse filosofie met mekaar te versoen. Die kenbaarheid van die metafisiese werklikheid kom gedurende die Middeleeue nooit werklik onder ' $n$ vraagteken nie, omdat die Grieks-Romeinse filosofie sy geldigheid behou en die aanvaarding van die kenbaarheid van God buite alle twyfel geplaas word deur die openbaring in die Bybel en die leer van die kerk.

Die Moderne Tyd het die opbloei van die natuurwetenskappe gebring en die filosofie, gedeeltelik onder die invloed van die natuurwetenskappe, het allerlei kritiese gedagterigtings na vore gebring. Met die oog op Kant was die kritiese inge- 
steldheid van David Hume (1711-1776) die belangrikste van al hierdie rigtings. Desondanks het die metafisika gedy, soos ons kan sien in die werke van filosowe soos Descartes (1596-1650), Spinoza (1632-1677), Leibniz (1646-1716), Wolff (16791754) en hulle aanhangers.

Siel, wêreld en God was die drie hoofbegrippe waarin die metafisika gekulmineer het, soos ons dit byvoorbeeld in die filosofie van Wolff (wat as die onmiddellike leermeester van Kant beskou moet word) vind. Dit was die taak van die psychologia naturalis om die rasionele siel te beskrywe. Hierdie rasionele psigologie word uit die aard van die denkende selfbewussyn opgebou, met ander woorde uit die aard van die ek as denkende wese. Die rasionele siel is die substansie wat die grond van alle denke, waarneming en innerlike bewuswording uitmaak. Dit is die subjektiewe eenheid en voorwaarde van alle bewussyn en selfbewussyn. Die rasionele kosmologie het die voorstelling gehandhaaf van 'n geslote rasionele totaliteit wat deur God ruimtelik en tydelik begrens is. Hierdie wêreld is die objektiewe voorwaarde vir alle kennis en die waarborg vir die uiteindelike kontradiksielose saamhang van alle waarheid.

Wolff se theologia naturalis, of spekulatiewe teologie, is die hart en die sluitstuk van die metafisika en daarmee van die hele wysbegeerte. God is die hoogste wese, die wese van alle werklikheid en daarmee die samevatting van die werklikheid as totaliteit, wat per slot van sake dieselfde is as die volkomenheid van die werklikheid. God is die finale waarborg van die werklikheid, die eenheid van die heelal en die uiteindelike kontradisielose saamhang van alle bewyssyn en waarheid.

Hierdie metafisika het (veral in Duitsland, maar ook in die res van die Westerse denkwerreld) gegeld as die hoogste vlug van wetenskaplike denke. Dit het die raamwerk gelewer waarbinne die teologie met gerustheid en wetenskaplike geborgenheid sy gang kon gaan. In Duitsland was dit die belangrikste fondamentsteen van die Duitse wêreldbeskouing en dit bereik sy hoogtepunt in die Aufklärung, met name in die filosofie van Christian Wolff.

Aanvanklik was dit ook Immanuel Kant (1724-1804) se vanselfsprekende oortuigings omdat dit die tradisie is waarin hy grootgeword het en sy onderwys ontvang het. Minstens nadat hy op universiteit gekom het, was Kant bewus van die kritiese stemme wat daar in die natuurwetenskap en veral in die filosofie onder natuurwetenskaplike invloed opgegaan het. Aanvanklik het die odium metaphysicum hom nie besonder gepla nie, omdat hy op daardie tydstip meer in die natuurwetenskappe belanggestel het en omdat dit in sy oë verskille, selfs teenstrydighede, op die vlak van die rede was wat mettertyd deur die rede opgelos moes en kon word. Teen 1763 praat hy egter reeds van die bodemlose afgrond en die oewerlose oseaan van die metafisika. Dit is egter eers in die 'transendentale Dialektik' van die Kritik der 
reinen Vernunft (1781) waar Kant werklik aandag aan die tradisionele metafisika gee. Die fundamentele punt van die metafisika, naamlik dat die leer aangaande siel, wêreld en God, wetenskaplik van aard is, takel hy sistematies en meedoënloos af totdat niks daarvan oorbly nie. Dit is 'n bekende gedeelte van Kant se wysbegeerte en ek gaan nie daarop in nie. Ek kan net noem dat Kant in hierdie kritiek in hoofsaak op een basiese punt van sy kennisleer bou, naamlik dat teoretiese (= spekulatiewe $=$ wetenskaplike) kennis altyd bestaan uit 'n bydrae van twee kante: In die eerste plek die bydrae van die rede en in die tweede plek die bydrae van die sintuiglikheid. Dit is die betekenis van Kant se beroemde uitspraak: 'Gedanken ohne Inhalt sind leer, Anschauungen ohne Begriffe sind blind' (KdrV B 75). Wetenskaplike uitsprake dra die kenmerk van aprioriteit omdat dit universeel en noodsaaklik is, maar dit verlaat nooit die grense van moontlike ervaring nie; daarom het dit altyd met die 'Erscheinung' en nooit met die 'Ding an sich' te make nie. Die metafisika kan geen aanspraak op wetenskaplikheid maak nie, omdat dit voorgee dat dit juis die 'an sich' kan ken en die grense van moontlike ervaring verlaat.

Die metafisika was altyd die middelman om wetenskap en teologie, rede en geloof, wetenskaplike gegewens en openbaringsgegewens met mekaar te versoen. In die Europese denke, veral die Duitse wêreldbeskouing, het dit oor die algemeen altyd gegeld dat die wetenskap die belangrikste stut vir die godsdiens is en dat daar geen werklike botsing tussen wetenskap en godsdiens kan wees nie, omdat die waarheid per slot van rekening een is. Die werk van Kant beteken dat hierdie verbintenis ná meer as tweeduisend jaar verbreek word.

Die verbreking van hierdie verbintenis is waarskynlik die belangrikste gebeurtenis in die geestesgeskiedenis van die Weste sedert die begin van die Moderne Tyd. Van al die moontlike terreine waarop 'n mens die invloed van hierdie gebeurtenis kan nagaan, wil ek my beperk tot enkele aspekte van die ontwikkeling van die Protestantse teologie.

Wanneer 'n mens Kant hoofsaaklik uit die samevattings van handboeke ken, geld Kant se kritiek op die metafisika as die finale beëindiging van die klassieke metafisika. Dit beteken ook die finale beëindiging van die spekulatiewe teologie. Kant is egter nie net die groot kenteoretikus nie, maar ook die grootste voorstander van die pligsetiek. Oor die algemeen word die etiek dan naas die kenteorie en die metafisika gestel, terwyl Kant se godsdiensfilosofie nog weer 'n vierde hoofstuk uitmaak.

So 'n siening misken die basiese feit dat Kant in ooreenstemming met sy tyd en sy voorgangers ' $n$ filosofiese sisteembouer was. Trouens, met die uitsondering van Hegel was Kant die grootste van die sisteembouers. Vir hom le die verskillende terreine van die filosofie nie langs mekaar nie, maar hang ten nouste met mekaar 
saam; almal is dele van die legkaart wat die hegsluitende geheel van die sisteem uitmaak.

Kant se kritiek op die metafisika en die spekulatiewe teologie het - soos hy self sê (KdrV B XXIV-XXV) - met die eerste oogopslag baie negatiewe effekte omdat dit die teoretiese rede baie sterk begrens. Die praktiese en die teoretiese rede is dieselfde rede, maar hulle werk met verskillende begrippe, beginsels en metodes. Sodat 'n sisteem moontlik kan wees, is dit dan noodsaaklik dat die rede in sy verskillende aktiwiteite homself nie moet weerspreek nie, hoewel die een nie die ander se ondersteuning nodig het nie. Die praktiese en die teoretiese, glo en weet, bestaan dus in harmonie met mekaar omdat (gesien van die kant van die teoretiese rede) die teoretiese rede se denkkategorieë, by uitstek die kategorie van oorsaaklikheid, net vir verskynsels geldig is, terwyl die mens sowel 'Erscheinung' as 'Ding an sich' is, en omdat (gesien van die kant van die praktiese rede) die praktiese rede met stellige sekerheid, op geldige gronde en met algemene geldigheid kan sé 'ek glo', sonder om aanspraak op die objektiewe gegewens van die verskynselwêreld (die sensibele wêreld) te maak. Die geloof staan op gelyke vlak met die wete, omdat die geloof net soos die wete in die rede gegrond is. Trouens, vir Kant het die praktiese rede die primaat bo die teoretiese rede, maar die harmonie tussen beide bly net moontlik wanneer die een sy grense ten opsigte van die ander bly handhaaf.

Kant is die groot voorstander van 'n etiek wat op gesindheid en plig gebou is en alle vorms van doeletiek verwerp. Hy stel sedelike goedheid onvoorwaardlik as intrinsieke goedheid en verwerp alle voorstelle wat die goedheid daarin vind dat dit 'n middel tot 'n doel is.

Dit is bekende stof en ek laat dit daar. Wat ek in hierdie verband wil uitlig, is dat die fundering wat hy aan sy etiek gee, in die hedendaagse weergawe daarvan gewoonlik op die agtergrond tree, en dat die godsdiensfilosofie wat hy in die fundering van die etiek opbou, so goed as heeltemal verdwyn. Aan die hoofgedagtes hiervan wil ek kort aandag gee.

- Die outonomie van die wil: Die pligsgebod is onvoorwaardelik, algemeen geldig en gegrond in die aard van die rede self. Dit is die suiwere praktiese rede wat self die wet vir die wil neerle. Dit is die sedewet of kategoriese imperatief wat suiwer uit agting vir die sedewet gehoorsaam word. Hierdie objektiewe kategoriese imperatief word subjektief wanneer Kant dit as persoonlike lewensbeginsels ('Maximen') formuleer. Die beginsels geld in die eerste plek die individu, maar is tegelyk ook die grondslag van die samelewing, wat duidelik spreek uit die formulering: 'Handle so, dasz du die Menschheit, sowohl in deiner Person als in der Person eines jeden anderen, jederzeit zugleich als Zweck, niemals 
blosz als Mittel brauchst' (Grundlegung BA 66-67). Die samelewing wat die beginsel handhaaf, is die 'Reich der Zwecke', waarin elke lid self wetgewend en tegelykertyd onderworpe aan die wet is (Grundlegung BA 74-75). Die suiwer praktiese rede lewer dus die beginsel van die selfwetgewing van die wil of outonomie van die individu, wat tegelykertyd die konstituerende beginsel van die samelwing is. Die 'Reich der Zwecke' laat ' $n$ mens onwillekeurig dink aan die vreedsame gemeenskap van die eindtyd soos die Christelike geloof dit voorstel.

- Die outonomie of vryheid van die wil is moontlik omdat ons wesens van twee wêrelde is. Ons is deel van die intelligibele wêreld en daarom vry, maar ons behoort ook tot die sintuiglike of sensibile wêreld, waardeur ons in die streng oorsaaklike ketting van natuurnoodwendigheid inskakel. Ons deelgenootskap aan die intelligibele wêreld het egter die primaat, omdat ons steeds selfwetgewer te midde van die natuurnoodwendigheid bly. Dit is die voorwaarde nie net van ons handelinge in gehoorsaamheid aan die sedewet nie, maar vir die moontlikheid van ons bestaan as sedelike wesens. Dit beteken dat ons die sedelikheid grond in iets wat verder en dieper as onsself en ons eie kenvermoë lê. Dit is 'n nuwe metafisiese prinsipe, wat wesenlik anders is as die prinsipes van die voorafgaande filosofie, omdat dit nie deur die teoretiese (spekulatiewe) rede bereik word nie, maar wel deur die praktiese rede. Hierdie nuwe metafisiese prinsipe is dus onkenbaar, omdat dit nie aan Kant se vereiste vir kennis, naamlik 'n bydrae sowel van die kant van die subjek as van die kant van die objek, voldoen nie. Ons kan hierdie nuwe metafisiese prinsipe 'n objek van geloof noem, maar Kant verkies om daarvan as postulate van die suiwere praktiese rede te praat. Hierdie postulate is vryheid, onsterflikheid en God.

Kant verstaan onder 'n postulaat 'einen theoretischen, als solchen aber nicht erweislichen Satz..., so fern er einem a priori unbedingt geltenden praktischen Gesetze unzertrennlich anhängt' (KdpV A 221, 222).

Diese Postulate sind nicht theoretische Dogmata, sondern Voraussetzungen in notwendiger praktischer Rücksicht, erweitern also zwar [verbetering van Akademie Ausgabe is invoeging van nicht na zwar. maar dit is nie Kant se oorspronklike teks nie) das spekulative Erkenntnis, geben aber den Ideen der spekulativen Vernunft im allgemeinen (vermittelst ihre Beziehung aufs Praktische P S D] objektive 
Realität, und berechtigen sie zu Begriffen, deren Möglichkeit auch nur zu behaupten sie sich sonst nicht anmaszen können.

(KdpV A 238)

Die eenvoudigste en verstaanbaarste uiteensetting van die drie postulate kry ons in die Kritik der praktischen Vernunft, eerste deel, tweede boek, wat ons in terme van die leer van die hoogste goed kan aanbied:

- Vryheid: Die hoogste sedewet word deur die suiwere praktiese rede self gegee as die kategoriese imperatief of onvoorwaardelike pligsgebod of die gebod om die goeie ter wille van die goeie na te streef. Dit is net moontlik wanneer ons veronderstel dat die mens vry is, wat berus op die feit dat ons lede van sowel die intelligibele as die sensibile wêreld is. Vryheid kan dus afgelei word uit en is die noodsaaklik vooronderstelling vir die moontlikheid van die sedewet.

- Die onsterflikheid van die siel: Die sedewet vereis die heiligheid van die wil, dit wil sê die volkome ooreenstemming van die gesindheid met die sedewet. Hierdie heiligheid van die wil is die hoogste goed (bonum supremum). Deug is die gesindheid van agting vir die plig ter wille van die plig self, waaruit die strewe na die hoogste goed vloei, maar is nie dieselfde as die heiligheid nie. In hierdie lewe bereik ons nooit die volkome heiligheid van die wil nie, terwyl ons strewe altyd gepaard gaan met die bewussyn dat ons die heiligheid moet kan bereik. Ons moet dus noodwendig veronderstel dat daar ' $\mathrm{n}$ vooruitgang ('Progressus') in die deug is wat na die heiligheid van die wil lei, maar omdat dit in hierdie lewe onbereikbaar is, moet ons die idee van die onsterflikheid van die siel aanvaar om die bereikbaarheid van die heiligheid moontlik te maak.

* God: Ons gehoorsaamheid aan die sedewet gaan met die verwagting gepaard dat ons geluk of ongeluk sal ontvang in die mate waarin ons deugsaam is. Hierdie ewewig bestaan egter nie op aarde nie, omdat ons dit ervaar dat die bose meesal gelukkig, en die deugsame meesal ongelukkig is. Die hoogste goed in die sin van die volkome geluk wat by die heiligheid hoort (bonum consummatum), is dus slegs hiernamaals bereikbaar, waar ons noodwendig die bestaan van God as oneindige mag, wysheid en goedheid moet veronderstel. Hy is die Skepper van die natuurlike wêreld en die Regeerder van die sedelike wêreld. Hy sal regverdig loon en straf afweeg soos dit die deug of die gebrek daaraan toekom.

Hierdie redenasie word dikwels Kant se etiese 'Godsbewys' genoem, ten onregte omdat Kant self dit nie as 'n Godsbewys aanbied nie, maar as die basis van sy rasionele geloof. 
Wat ek hier aangebied het, is die hoofsaak van Kant se metafisika wat op die praktiese rede gebou is. Dit is duidelik dat ons daarmee vol op die terrein van die godsdiens en die teologie beland het. Die gedagtes wat hierbo saamgevat is, is dan ook die grond en deel van wat dikwels Kant se moraalteologie of rasionele godsdiens genoem word. Dat Kant self hiervan bewus was, word getoon deur sy Religion innerhalb der Grenzen der bloszen Vernunft. Hierin kom vier hooftemas ter sprake:

- Boosheid: Kant wil nie van sonde praat nie, maar van 'das radikale Böse in der menschlichen Natur'. Die mens het natuurlik en aangebore 'n 'Hang zum Bösen', wat daarin tot uiting kom dat hy uit vrye wil die sedelike orde wat op die sedewet en veral die persoonlike grondbeginsels berus, omkeer. In plaas van op die sedelik goeie is die mens op selfbevrediging toegespits. Daarom is daar vir elke mens 'n totale omkering van gesindheid, 'n wedergeboorte, 'n aantrek van die nuwe mens nodig, wat in 'n geleidelike verandering van die gesindheid en die ewe geleidelike vordering in die rigting van heiligheid verwerklik word.

- Onder die ewige Seun van God moet ons die ideaal van die volmaakte mens verstaan. Dit is die ware doel van die skepping. Die saligmakende geloof beteken nie om aan 'n historiese persoon, Jesus van Nasaret, te glo nie, maar om die ideaal van die sedelike volkomenheid met beslistheid na te streef.

- Die kerk is die gemeenskap wat leef volgens die sedewet, 'n sedelike volk van God wat mekaar bystaan en versterk in pligsbetragting. Die grondslag van die kerk is die geloof van die suiwere praktiese rede, maar weens die swakheid van die menslike natuur is die vorming en instandhouding van die kerk goed.

- Vals godsdiens: Die Christelike geloof kan 'n suiwer rasionele geloof ('reiner Vernunftglaube') of 'n openbaringsgeloof (fides statutaria) wees. Eersgenoemde kan deur enigeen aangeneem word (fides elicita), terwyl laasgenoemde 'n geloof op gesag (fides imperata) is (Religion B 247-248). Die openbaringsgeloof berus op geskrifte (hoofsaaklik die Bybel), dogmas en voorskrifte van die 'Pfaffentum', wat 'n onveranderlike geloof in stryd met die rede beveel en die mens probeer beweeg om God te dien met 'n lewenswandel buite die suiwer sedelikheid wat op die rede gegrond is. Dit is alles bygeloof en vals godsdiens. Die historiese kerk met alles wat dit insluit, moet daarop-ingestel wees om homself oorbodig te maak deur sy openbaringsgeloof al meer in rasionele geloof te verander. Die onveranderlikheid van die kerk se geloof is bygeloof en 'n oortreding teen die mens se natuur, omdat die mens sedelik bestem is tot geleidelike vooruitgang.

Benewens hierdie hooftemas behandel Kant 'n aantal newesake by wyse van 'allgemeine Anmerkungen'. Die belangrikste is: 
- Genadewerkinge kan nie bewys word nie, maar ook nie as onmoontlik bewys word nie. Die enigste betekenis wat dit kan he, is die sedelike verbetering van die persoon en dit is veel beter om self aan hierdie sedelike verbetering te werk as om vir genade te wag. Aanspraak op die ervaring van hemelse inwerkinge is dweepsieke godsdienswaansin.

-Wonders wat die wette van die ervaring weerspreek, verwerp Kant heeltemaal. Wonders moet rasioneel verklaarbaar wees, wat beteken dat dit geen wonders meer is nie.

- Christelike verborgenhede is alleen van waarde wanneer dit rasioneel verduidelik kan word (wat meebring dat dit nie meer 'n verborgenheid is nie) en sedelik bevorderlik is, so byvoorbeeld wanneer die drie-eenheid van God verduidelik word as God die heilige wetgewer, die welwillende regeerder en die regverdige regter.

- Kultushandelinge is belangrik as uitdrukking van sedelike gesindheid en gemeenskap. Om die seremonies (soos doop en nagmaal) as genademiddels te beskou is waansin.

Daarmee gaan ek volstaan en afsluitend aan sommige van die belangrikste Protestantse denkstruture wat hierby aansluit, aandag gee.

- Ter aanvang wil ek wys op die merkwaardige feit dat Kant soveel aandag aan so 'n groot verskeidenheid aspekte van die Christelike godsdiens gee. God, onsterflikheid, die bose, kerk, heiligheid, bekering, versoening, straf en so meer ontvang alles aandag. Dit is ook merkwaardig dat Kant nêrens die Christelike godsdiens of basiese gedagtes van die Christelike godsdiens verwerp nie. Inteendeel, hy maak deurgaans die indruk dat hy butengewoon simpatiek daarteenoor staan. Die verklaring hiervoor moet ons in sy piëtistiese huislike agtergrond soek. Hierdie agtergrond maak dat hy die waarheid van die Christelike geloofsgoed en die sinvolheid van die Christelike godsdiens bo alle twyfel stel.

Dit beteken allermins dat Kant 'n ortodokse gelowige is. Hy bly steeds filosoof, en hoewel hy in baie opsigte die Aufklärung deurbreek, bly hy steeds Aufklàrer. Langs die weg van rasionalistiese omvorming en herinterpretasie van die kerklike openbaringsgeloof maak Kant van die Christelike godsdiens 'n filosofiese sisteem, wat op bepaalde metafisiese postulate berus, maar wesenlik 'n etiek is. Godsdiens is vir Kant sinvol in soverre dit sedelike betekenis het. Dit impliseer die rasionele rekenskapgee van die sedelikheid as sodanig, die aanwys van die sedewet waarvolgens die individu moet lewe, die sedelike orde- 
ning en opvoeding van die samelewing en so meer. Wat nie as rasionele etiek interpreteer kan word nie, het vir Kant geen reg op bestaan nie.

- In die grondgedagtes van sy eie filosofie toon Kant strukture wat ons as wesenlik Protestantse strukture kan aandui. Ek wys net op die twee belangrikste:

- Soos hierbo aangedui is, vertoon die metafisiese denke voor Kant 'n kontinuïteitstruktuur. Daarmee word bedoel dat die kennende bewussyn die totaliteit van die syn, insluitende God, in een aaneenlopende lyn kan bereik en insluit. Kant handhaaf daarteenoor 'n diskontinuïteitstruktuur, die model van die grens tussen die teoretiese en die praktiese rede. Hierdie struktuur korrespondeer met die Protestantse model wat God as onkenbaar beskou, wat 'n grens tussen mens en God stel wat op geen wyse deur die mens deurbreek kan word nie, sodat God slegs kenbaar kan wees wanneer Hy uit vrye genade en liefde Hom aan die mens openbaar.

- Wesenlik van Kant se etiek is die onderskeiding van die hipotetiese en die kategoriese imperatief. In die eerste plek is die onvoorwaardelike eis van die kategoriese imperatief 'n parallel van die onvoorwaardelike eis van God in sy wet. Tweedens is daar geen wyse waarop 'n mens kan bepaal of iemand se handeling met die doel van selfbevoordeling of uit onvoorwaardelike gehoorsaamheid aan die sedewet verrig is nie. Per slot van rekening hang dit van die persoon se gewete af of hy suiwer gehoorsaam aan die sedewet handel of nie. Hier het ons 'n analogie aan die Protestantse beskouing van geloof. Geloof as antwoord op die werking van die Heilige Gees is algeheel 'n saak van die innerlike van die persoon en geen mens kan hieroor' $n$ oordeel vel nie.

- Teen die einde van die agtiende eeu is daar reeds 'n baie sterk intellektuele elite in Europa. Hierdie elite was veral baie sterk onder die invloed van die natuurwetenskappe wat sedert die begin van die Moderne Tyd so geweldig opgebloei het. Kant het self ook hierdie invloed ondergaan, maar was ook een van die kragtigste figure om hierdie invloed uit te brei, soos 'n mens baie duidelik byvoorbeeld in sy Allgemeine Naturgeschichte und Theorie des Himmels (1755) kan sien. Laasgenoemde werk is ook 'n baie duidelike uitbeelding van die nuwe wêreldbeeld wat in Europa geldig geword het. Hierdie wêreldbeeld en die beskouings van die Christelike godsdiens het sterk verskil. Die byderwetse wetenskaplike gemeenskap en die verligte burgery, onder wie dit 'n mode was om wetenskaplike aktiwiteite en beskouings te ondersteun, het in 'n groot 
mate negatief teenoor die Christelike beskouings gestaan, behałwe teenoor 'n liberaal geïnterpreteerde Christelike sedeleer (vgl Löwith, Plessner, Hirsch). Hierdie gemeenskap, wat geweldig invloedryk was en in invloed gegroei het, word baie sterk deur Kant beïnloed.

Filosofies bet Kant die hele ontwikkelde Europa beïnvloed, maar teologies was sy invloed op die Protestantse kerke verreweg die sterkste, wat te verwagte is as ' $n$ mens die 'Protestantse strukture' van sy denke in ag neem. Wat in besonder baie moontlikhede geopen het, was die feit dat Kant (in sy terminologie) aan die metafisiese denke geen wetenskaplike waarde heg nie en die etiek (daarmee saam die godsdiens) op geloof bou. Kant se beskouing van geloof is weliswaar heeltemal rasionalisties, maar selfs Kant ontkom nie daaraan dat die geloof per slot van rekening in sy laaste grondslae die element van keuse en beslissing impliseer nie. Veral hierdie element is deur denkers ná Kant sterk na vore gebring.

- Die feit dat Kant sy moraalteologie op (wetenskaplik nie-bewysbare) postulate bou, het 'n opening vir die ateïsme van die negentiende eeu geskep. Vryheid is selfevident en onbetwyfelbaar. Trouens, die Moderne Tyd en veral die negentiende eeu, is met vryheid behep. In die postulate van onsterflikheid en God is daar egter niks wat die aanvaarding daarvan gebiedend maak nie en staan dit ' $n$ mens vry om teen die aanvaarding van onsterflikheid en God te besluit. Ons kan die redenasie van Ludwig Feuerbach as voorbeeld neem.

Feuerbach se benadering van die godsdiens is wesenlik dieselfde as dié van Kant. In sy hoofwerk, Das Wesen des Christenthums (1841), maak hy erns van elke aspek van die Christelike godsdiens, tot selfs in klein besonderhede. In terme van sy basiese stelling, die geheim van die teologie is die antropologie, volg hy die resep van Kant, naamlik om in die Christelike godsdiens se begrippe en voorstellings basiese en belangrike waarhede te sien, maar waarhede wat verwronge is, omdat dit heeltemal herinterpreteer moet word om die waarheid daarvan uit te haal. Die herinterpretasie is egter ook die vernietiging van die Christelike godsdiens, wat Feuerbach se doel is. Waar Kant simpatiek teenoor die godsdiens is, is Feuerbach antipatiek. Daarom kan Feuerbach roerend met Hegel eens wees: Hegel het, net soos Kant, die godsdiens 'aufgehoben' (Hegel se term wat deur Feuerbach en ander jong-Hegeliane beklemtoon word) tot filosofie, maar Feuerbach is ironies in sy instemming. Waar Hegel onder 'aufheben' verhef verstaan, dit wil sê op 'n hoër vlak plaas, daar verstaan Feuerbach 
daaronder ophef, dit wil sê tot niet maak. Godsdiens opgehef tot filosofie is as godsdiens vernietig.

Feuerbach en andere doen besondere moeite om aan te toon dat die aanvaarding van onsterflikheid en God nie vir die voer van 'n hoogstaande sedelike lewe nodig is nie.

Kant se skeiding van die teoretiese en die praktiese rede, wat daarop uitloop dat die metafisika vir hom geen kenniswaarde het nie, gee die geleentheid aan veral die natuurwetenskaplikes om hulle rug op die godsdiens te draai. Dit is 'n tendens wat in die agtiende eeu reeds baie sterk na vore kom (byvoorbeeld by Holbach, Helvetius, Destutt de Tracy en so meer), maar Kant lewer vir die eerste keer die filosofiese ontwerp wat gebruik kan word om dit te regverdig. Feuerbach maak uitgebreide gebruik hiervan deur die reduksie van die mens tot bewegende materie, wat die finale bewys van die valsheid van die godsdiens is. Ons sien dit die duidelikste in sy geskrif Der Mensch ist was er isst, waar hy veral gebruik maak van die bevindinge van Moleschott en Voigt.

Dit is opvallend dat die ateîsme van die negentiende eeu by uitstek 'n Protestantse verskynsel is.

- Die ateïsme van die negentiende eeu was egter vir die grootste gedeelte nog nie sosiaal aanvaarbaar nie en was meer 'n verskynsel van die revolusionêre buiterand van die samelewing. Die negentiende-eeuse Protestantse sosiale establishment sluit nog godsdiens en kerk in, maar dan 'n sterk liberaal geïnterpreteerde beskouing daarvan. Onder liberale interpretasie verstaan ek hier die beskouing dat die grondslae en die vorme van die godsdiens nie in die eerste plek in die openbaring van God gesoek moet word nie, maar in die individu self. Hierdie denkrigting met al sy variasies, waarvan ons enkele aanstip, laat Kant in die negentiende eeu bekend staan as die filosoof van die Protestantisme.

'n Baie sterk stroming het Kant nagevolg en van die Christelike godsdiens 'n rasionalistiese filosofiese sisteem gemaak. Allerhande ou en nuwe filosofiese strominge is op verskillende maniere ingewerk, maar die grondslag het dieselfde gebly, naamlik Kant se rasionalistiese omvorming van die Christelike openbaringsgeloof.

Die etiese strominge het dit met mekaar in gemeen gehad dat godsdiens wesenlik om die sedelike lewe gaan en daarom op die heiliging van die mens toegespits is. Daar was egter groot verskille onderling en wel in die mate waarin daar aansluiting by die Bybel gevind is. Die mees behou- 
dende etiese rigtings het die normatiewe gesag van die Bybel en die noodsaaklikheid van Jesus as voorbeeld bo enige twyfel gestel. Die mees vrysinnige rigtings het byna nog net die Bergpredikasie as hoogste ideaal aanvaar en naas die Bybel filosowe soos Spinoza en ook ander godsdienste met ewe veel gesag gestel.

Friedrich Schleiermacher (1768-1834) is al meer as een keer die leermeester van die Duitse Protestantisme van die eerste helfte van die negentiende eeu genoem. Hy is sterk onder die invloed van die Romantiek en vind die grondslag van die godsdiens in 'n subjektiewe 'schlechthinnige Abhängigkeisgefühl'. In hierdie opsig is hy verder van Kant verwyder as die meeste ander strominge, maar erken sy sterk beinvloeding deur Kant en handhaaf die Kantiaanse struktuur van die omvorming van die openbaringsgeloof tot 'n subjektief gefundeerde menslike sisteem, hetsy rasionalisties, hetsy eties, hetsy misties van aard. Dit is die patroon van die hele Protestantse teologie van die negentiende eeu, met die enkele uitsondering van Sören Kierkegaard.

- Die negentiende eeu kan met reg die eeu van revolusie genoem word. Dit begin teen die einde van die agtiende eeu met die Amerikaanse vryheidsoorlog en die Franse Revolusie. In die oorsese kolonies van die Europese lande vind 'n hele aantal revolusies plaas, maar filosofies is hulle bloot swak nabootsings van die gedagtes in Europa. Die revolusies in Europa gaan gepaard met 'n filosofies-ideologiese stryd wat van die grootste belang is. Hoewel dit net indirek met Kant te make het, is dit opvallend dat die revolusionêre denkers van die negentiende eeu hoofsaaklik uit 'n Protestantse agtergrond kom en sterk deur Kant beinvloed is. Voorbeelde is Ludwig Feuerbach, wat as Protestantse teologiese student op universiteit begin het; Karl Marx, wat van Joodse afkoms was, maar wie se familie in 'n vrysinnige Protesiantisme oorgegaan het; en Bruno Bauer, vrysinnige Protestantse professor in teologie. Vir hierdie mense het die verwerping van die politieke bestel noodwendig die verwerping van die Christelike godsdiens en die kerk ingesluit, omdat politiek, godsdiens en kerk 'n onskeibare totaliteit in die establishment van die tyd uitgemaak het.

Ideologie, veral soos dit in die uiterste vorme van die Fascisme, NasionaalSosialisme en Kommunisme ontwikkel het, is al dikwels 'n religie genoem en met die Christelike godsdiens vergelyk. Hiervan is Nikolaus Berdjajev maar net een voorbeeld. So ' $n$ vergelyking berus gewoonlik op 'n vals beskouing van die Christelike godsdiens, maar bevat dikwels tog elemente van waarheid. Binne ons verband kan daarop gewys word dat die struktuur van die ideologiese denke 
onder andere daarop berus dat dit 'n hoogste waarde postuleer (volk, staat, arbeiders as klas ens) en dat hierdie waarde as sodanig, asook die postuleer daarvan as hoogste waarde, nie die resultaat van wetenskaplike denke is nie, maar as selfevidente vooronderstelling gestel word. Daarbenewens is die ideologiese denke primêr gerig op die stel van 'n norm vir die praktyk en die verandering van die praktiese bestaan van die samelewing.

- In die twintigste eeu het daar van die kant van die Protestantse teologie baie sterk reaksie teen Kant se gedagtes gekom. Die sterkste reaksie kom van die kant van die dialektiese teologie. 'n Bespreking hiervan gaan ons te lank neem, maar ek kan na Karl Barth en veral Emil Brunner verwys, by name na laasgenoemde se Das Gebot und die Ordnungen. Juis Kant geld vir Brunner as die voorbeeld van 'n mens-gesentreerde godsdiens en as die teendeel van wat die openbaring van God ons leer. Die sterkste aanval loods Brunner op Kant se voorstelling van Christus as voorbeeld en van sonde as 'das radikale Böse'. Brunner beklemtoon dit dat dit in die Christelike geloof nie gaan om sedelike verbetering nie, maar om verlossing; en Christus is nie primer ' $n$ voorbeeld vir die sedelike lewe van die mens nie, maar die sondaar se Verlosser uit die dood. Van alle filosowe kom Kant die naaste aan die Bybelse beskouing van die sonde wanneer hy van 'das radikale Böse' en die mens se natuurlike geneigdheid tot die kwaad praat. Dit is egter nie die Bybelse begrip van sonde nie. Dit bly'n blote sedelike aangeleentheid, terwyl sonde die oortreding teen God is wat nie deur verbetering uitgewis kan word nie, maar slegs deur die vergifnis van God op grond van die lyding van Christus.

Kant se denke beteken nie net 'n radikale wending in die filosofie nie, maar in baie opsigte ook in die teologie.

\section{Literatuurverwysings}

Barth, K 1950. Kirchliche Dogmatik. Zürich: Zollikon.

Berdjajev, N 1925. Der Sinn der Geschichte. Darmstadt: Otto Reichl.

- 1947. The Russian idea. London: Geoffrey Bles.

Broad, C D 1978. Kant: An introduction. Cambridge: Cambridge University Press.

Brunner, E 1939. Das Gebot und die Ordnungen. Zürich: Zwingli.

Feuerbach, L 1841. Das Wesen des Christenthums, in Sämmtlich Werke, 6. Band, 1903vv. Stuttgart: Wilhelm Bolin \& Friedrich Jodl.

Hirsch, E 1952. Geschichte der neueren evangelischen Theologie im Zusammenhang mit den allgemeinen Bewegungen des europäischen Denkens. 4. Band. Gütersloh: Bertelsmann. 
Kant, I* 1755. Allgemeine Naturgeschichte und Theorie des Himmels.

-- 1781, B 1787. Kritik der reinen Vemunfi.

... 1785, B 1786. Grundlegung zur Metaphysik der Sitten.

-.- 1788. Kritik der praktischen Vermunft.

-- 1793, B 1794. Religion innerhalb der Grenzen der bloszen Vermunfi.

Löwith, K 1941. Von Hegel zu Nietzsche: Der revolutionäre Bruch im Denken des neunzehnten Jahrhunderts. Europa: Zürich.

Plessner, H 1935. Das Schicksal deutschen Geistes im Ausgang seiner bürgerlichen Epoche. Zürich: Niehaus.

Vleeschauwer de, H J s a. Geskiedenis van die Wysbegeerte in die Weste, Band III: Die Wysbegeerte van die Moderne Tyd. Kaapstad: Nasou.

-.- 1962. The development of Kantian thought. London: Nelson.

- Die uitgawe van Kant wat gebruik is, is die van die Wissenschaftliche Buchgesellschaft van Darmstadt, versorg deur Wilhelm Weischedel. 